\title{
Antibacterial Activity of Methanolic Extracts, Decoction and Isolated Triterpene Products From Different Parts of Birch, Betula pendula, Roth
}

\author{
Kemal Duric ${ }^{1}$, Elvira Kovac-Besovic ${ }^{1}$, Haris Niksic ${ }^{1} \&$ Emin Sofic ${ }^{2}$ \\ ${ }^{1}$ Faculty of Pharmacy, University of Sarajevo, Bosnia and Herzegovina \\ ${ }^{2}$ Faculty of Science, University of Sarajevo, Bosnia and Herzegovina \\ Correspondence: Kemal Duric, Faculty of Pharmacy, University of Sarajevo, Bosnia and Herzegovina. E-mail: \\ kemalduric@gmail.com
}

Received: December 19, 2012 Accepted: May 20, 2013 Online Published: May 27, 2013

doi:10.5539/jps.v2n2p61

URL: http://dx.doi.org/10.5539/jps.v2n2p61

\begin{abstract}
Five methanolic extracts obtained from different parts of birch, Betula pendula, Roth. (external and internal bark, flowers, leaves and buds), were evaluated for their antibacterial activity in this study. Triterpene compounds, betulin, betulinic acid, oleanolic acid and lupeol, were isolated from the external parts of birch bark using the method of dry column chromatography (DCC) as well as preparative thin layer chromatography (TLC). These compounds were also investigated for their antibacterial activity. Taking into account that decoction is the most commonly used pharmaceutical form of herbal drug, decoctions made from external bark, leaf, flower and bud were investigated for their antibacterial activity. Antibacterial screening, against selected Gram-positive bacteria, Bacillus subtilis ATCC 6633, Staphylococcus aureus ATCC 6538P and Gram-negative bacteria, Escherichia coli ATCC 8739 and Pseudomonas aeruginosa ATCC 9027 was carried out. The methods of diffusion and dilution were used for this investigation according to European Pharmacopoea, 1996. The most prominent antibacterial activity showed oleanolic acid against bacterial species Staphylococcus aureus, expressed as minimal inhibitory concentration (MIC): $1.25 \%$ and Bacillus subtilis MIC: $0.625 \%$. Escherichia coli showed resistance on all investigated samples.
\end{abstract}

Keywords: methanolic extracts, birch, antibacterial activity, betulin, betulinic acid, lupeol, oleanolic acid

\section{Introduction}

The antimicrobial activity has formed the basis of many applications, including pharmaceuticals, row and processed food preservations, alternative medicine and natural therapies. This aspect assumes a particular relevance due to an increased resistance of some bacterial strains to the most common antibiotics and antimicrobial agents for food preservation (Grainger, 2001; Bruneton, 1999).

Widespread availability of all birch species results in everyday usage for different purposes of this plant species. European pharmacopoeia contains birch leaf, Betulae folium, Betula pendula, Betulaceae, as monograph, but other parts of the birch plant has a long history of medicinal use in different countries and cultures to cure skin diseases especially eczema, infections, inflammations, rheumatism and urinary disorders (Shikov, 2011; Germano, 2012). Previous phytochemical investigations of this species led to the identification of flavonoids, triterpenes, saponins, tannins, substances that have many important pharmacological activity including antibacterial, anti-inflammatory, diuretic, anti-HIV and anticancer activity (Dehelean, 2012; Drag, 2009; Dorr, 2011; Soica, 2012).

The purpose of this study is to evaluate various new potential antibacterials against a few common disease-causing bacteria, and to determine the minimal inhibitory concentration of test compounds and extracts with antibacterial activity. With respect to this, various extracts including decoctions and methanolic extracts of Betulae cortex, Betulae gemmae, Betulae folium and Betulae flos were prepared and tested for their antibacterial activity. Very important biologically active compounds, triterpene saponins of $\beta$-amirin type and lupeol type, are constituents of birch cortex (Kovac-Besovic, 2009). We isolated some of these compounds (betulin, betulinic acid, lupeol and oleanolic acid) and tested for their antibacterial activity. The methods of diffusion and dilution were used for this investigation (European Pharmacopoea, 1996). 


\section{Materials and Methods}

\subsection{Plant Materials Collection and Identification}

Plant materials were collected from the Sarajevo region of Bosnia and Herzegovina in 2010, in dry and sunny weather during the periods typical for collecting individual plant parts. Leaves were collected in the spring, at the end of May-beginning of June, when fully developed; flowers were also collected in the spring during the month of June. Buds were collected in early spring before leafing, at the end of April.

Birch bark was collected from young trees $25-30 \mathrm{~cm}$ in diameter during autumn. The bark was peeled in large longitudinal strips, which contained internal brown and external white colored layers. The bark was separated into internal and external bark by immersing it completely for 10 minutes in water. The porous internal part of the bark absorbed the water while the hydrophobic external part separated to the surface of the water. After the separation was done, internal and external parts of the bark were dried in the oven at $45^{\circ} \mathrm{C}$ for two hours. Plant materials (Betulae cortex, Betulae gemmae, Betulae folium and Betulae flos) were obtained from Betula pendula, identified by Prof. Samir Dug and voucher specimen No.1056 was deposited at the herbarium of the Department of Biology, Faculty of Sciences, University of Sarajevo, Bosnia and Herzegovina.

\subsection{Extraction Procedure}

Each herbal drug was powdered in a blender (50 g each) and extracted with $250 \mathrm{ml}$ of acetone $(99.5 \%)$ at water bath $\left(60^{\circ} \mathrm{C}\right)$ with a back-cooler for two hours. Acetone extract was eliminated and afterward the drug was twice extracted with acetone $(150 \mathrm{ml})$ applying the same conditions, but in the duration of 30 minutes. The remaining part of the drug, after the extraction with acetone, was dried at water bath (by heating in order to definitely eliminate the solvent we used). Such dried and treated drug was extracted with $250 \mathrm{ml}$ of $80 \%$ methanol in the same way and under the same conditions as described with acetone extractions. Methanol portions $(250 \mathrm{ml}+150$ $\mathrm{ml}+150 \mathrm{ml}$ ) were unified and solvent evaporated on rotavapor. Acetone extraction was performed prior to methanol extraction in order to eliminate undesirable substances and products like resins, oils, etc. Thin layer chromatography method was used to control the presence of triterpene compounds in both fractions (acetone and methanol). Triterpene components were concentrated in methanolic fractions.

After solvent evaporation, different dry methanolic extracts of the investigated plant parts were obtained and used for further investigation.

\subsection{Isolation of Triterpene Compounds}

Triterpene compounds were isolated from external birch bark. Methanolic fraction of Betulae cortex was prepared in the same way described above in an extraction procedure with the difference that solvent (methanol) was not evaporated but added with water, which produced a huge amount of white sediment, separated by filtration under vacuum through Büchner's funnel, using filter paper MN $640 \mathrm{~m}$, white ribbon (Macherey-nagel, Germany). Sediment was dried in an oven $\left(60^{\circ} \mathrm{C}\right)$ for one hour and was subsequently used for isolation of triterpenes by DCC and TLC.

\subsubsection{Conditions for DCC}

Naylon tube (Nylon Tubing for DCC, 2" x 100', Sorbtech, USA) was closed in one of its two extremities with a stringent ribbon and security clip. The column was than filled with a sorbent (silica gel DCC, 63-200 um, Merck, Germany) up to $3 / 4$ of its overall height. Fillment was performed in small portions with a constant pressure of content by beating the firm basis.

The dry purified methanolic extract was mixed with the same quantity of sorbent and applied as a level layer on top of the column. Solvent mixture: benzene - ethyl acetate - formic acid (36:12:5), was passed through entire length of column. Subsequently the column was settled in a horizontal position and than 1/16 of a column was cut vertically. That part was sprayed with reagent 4-methoxybenzaldehyd - sulphuric acid in order to identify separated triterpene components. The sprayed part was arranged in parallel to the rest of the column in order to mark the separated components in the rest of the column. At those places the column was cut with knife (scalpel) and different fractions were gathered into laboratory glasses. Silica-gel was separated by filtration. The purity and identity of separated components were further analyzed by the TLC method.

\subsubsection{Conditions for TLC}

Isolated substances $(20 \mathrm{mg})$ were dissolved in methanol $(10 \mathrm{ml})$ and this solution $(20 \mu \mathrm{l})$ was used for TLC. Standard substances $(10 \mathrm{mg})$ were dissolved in methanol $(10 \mathrm{ml})$ and the solution $(20 \mu \mathrm{l})$ was used for chromatographic analysis. Adsorbent: silica gel $\mathrm{GF}_{254}$, Merck Dürmsttadt, Germany, finished plates; System for development: benzene - ethyl acetate - formic acid (36:12:5); Visualization: 4-methoxybenzaldehyd - sulphuric 
acid.

\subsection{Samples Preparation}

Previously prepared dry methanolic extracts of investigated plant materials, Betulae flos, birch flower (F), Betulae cortex ex., external birch bark (B. ex), Betulae cortex in., internal birch bark (B.in), Betulae folium, birch leaf (L), Betulae gemma, birch buds (B), were dissolved in pure DMSO as $5 \%$ solutions.

Decoctions $(10 \%)$ of external bark $\left(D_{B e x}\right)$, leaf $\left(D_{L}\right)$, flower $\left(D_{F}\right)$ and buds $\left(D_{B}\right)$ were prepared too. Plant material $(10 \mathrm{~g})$ was boiled in water $(100 \mathrm{ml})$ for 30 minutes. After filtration, decoctions were concentrated to the volume of $10 \mathrm{ml}$ and used for antibacterial investigation.

Isolated products, lupeol (lup), betulin (bet), oleanolic acid (oa) and betulinic acid (ba) were prepared as solutions (5\%) in pure DMSO

Table 1. Signature of test samples used in antibacterial investigation

\begin{tabular}{llll}
\hline Signature & Test sample & Signature & Test sample \\
\hline lup & lupeol (isolated) & $\mathrm{B}$ & Buds extract (MeOH) \\
bet & betulin (isolated) & $\mathrm{D}_{\mathrm{Bex}}$ & bark (external) decoction \\
ba & betulinic acid (isolated) & $\mathrm{D}_{\mathrm{L}}$ & leaf decoction \\
oa & oleanolic acid (isolated) & $\mathrm{D}_{\mathrm{F}}$ & flower decoction \\
F & flower extract (MeOH) & $\mathrm{D}_{\mathrm{B}}$ & buds decoction \\
B.ex & bark (external) extract $(\mathrm{MeOH})$ & $\mathrm{C}$ & control (pure DMSO) \\
B.in & bark (internal) extract $(\mathrm{MeOH})$ & $\mathrm{S}$ & Standard antibiotic \\
L & leaf extract $(\mathrm{MeOH})$ & & \\
\hline
\end{tabular}

\subsection{Test Bacterial Species}

Gram-positive bacteria - Bacillus subtilis ATCC*6633, Staphylococcus aureus ATCC $6538 \mathrm{P}$

Gram-negative bacteria - Escherichia coli ATCC 8739, Pseudomonas aeruginosa ATCC 9027

*ATCC - American Type Culture Collection

2.6 Standard Substances - Antibiotics and Their Culture Media Table 1

Table 2. Antibiotic standards used for antibacterial investigation

\begin{tabular}{lclc}
\hline Antibiotic & Unit $(\mu \mathrm{g} /$ disc $)$ & Microorganism & *Culture media \\
\hline Ciprofloxacin & 5 & P. aeruginosa, S. aureus & $A$ \\
Gentamicin sulphate & 30 & E. colli & $B$ \\
Pencilin & 6 & B. subtilis & $E$
\end{tabular}

*Culture media A, B and E for single microorganisms according to Europaean Pharmacopoea $5^{\text {th }}$ Edition.

\subsection{Diffusion Method}

\subsubsection{Preparation of Inoculates}

Bacterial inoculates were prepared by cultivating on Casein soya bean digest Agar (Composition: Pancreatic digest of casein $15.0 \mathrm{~g}$; Papaic digest of soya bean $5.0 \mathrm{~g}$; Sodium chloride $5.0 \mathrm{~g}$; Agar $15.0 \mathrm{~g}$; Purified water to $1000 \mathrm{~mL}$ ). The test organism was grown in the culture for 24 hours at the temperature of $35-37^{\circ} \mathrm{C}$. A suspension was prepared by washing off the growth and diluting with saline water, followed by mixing in an agitator to achieve homogeneity. Afterwards, the transparency was measured by a colorimeter. The aim was to obtain transparency in the range of $90-95 \%$, in other words $10^{5}-10^{6} \mathrm{CFU} / \mathrm{ml}$ (Columny Forming Units). 


\subsubsection{Preparation of Culture Media}

Base culture medias were prepared in such a manner where they were first sterilized for 15 minutes at $121{ }^{\circ} \mathrm{C}$ in autoclave, followed by dissolution in a Koch pot and let cool at $50{ }^{\circ} \mathrm{C}$. The base should be at a temperature of $48-50{ }^{\circ} \mathrm{C}$ in order to be liquid and dispersible, but still sufficiently cool to avoid pasteurization of the inoculated sample. The composition of the culture medias A, B and E, used for different bacterial strains, were presented in Table 3.

Table 3. The composition of the base culture medias (A, B and C)

\begin{tabular}{|c|c|c|c|c|c|}
\hline \multicolumn{2}{|l|}{ Medium $A$} & \multicolumn{2}{|l|}{ Medium B } & \multicolumn{2}{|l|}{ Medium $E$} \\
\hline Peptone & $6 \mathrm{~g}$ & Pancreatic digest of casein & $17 \mathrm{~g}$ & Peptone & $5 \mathrm{~g}$ \\
\hline $\begin{array}{l}\text { Pancreatic digest of } \\
\text { casein }\end{array}$ & $4 \mathrm{~g}$ & Papaic digest of soya bean & $3 \mathrm{~g}$ & Meat extract & $3 \mathrm{~g}$ \\
\hline Beef extract & $1.5 \mathrm{~g}$ & Sodium chloride & $5 \mathrm{~g}$ & $\begin{array}{l}\text { Disodium } \\
\text { phosphate, } 12 \mathrm{H}_{2} \mathrm{O}\end{array}$ & $26.9 \mathrm{~g}$ \\
\hline Yeast extract & $3 \mathrm{~g}$ & $\begin{array}{l}\text { Dipotassium hydrogen } \\
\text { phosphate }\end{array}$ & $2.5 \mathrm{~g}$ & Agar & $10 \mathrm{~g}$ \\
\hline Glucose monohydrate & $1 \mathrm{~g}$ & Glucose monohydrate & $2.5 \mathrm{~g}$ & Water to produce & $1000 \mathrm{ml}$ \\
\hline Agar & $15 \mathrm{~g}$ & Agar & $1 \mathrm{~g}$ & & \\
\hline \multirow[t]{2}{*}{ Water to produce } & $\begin{array}{l}1000 \\
\mathrm{ml}\end{array}$ & Polysorbate & $10 \mathrm{~g}$ & & \\
\hline & & Water to produce & $1000 \mathrm{ml}$ & & \\
\hline
\end{tabular}

\subsubsection{Inoculation of Culture Media and Depositing of Tested Samples}

Culture media $A, B$ and $E$, which European Pharmacopoeia prescribes, were used in this investigation. The tested sample solutions were applied $(100 \mu \mathrm{L})$ in cavities prepared in agar with a sterile cylinder. After incubation (about 18 hours at $37{ }^{\circ} \mathrm{C}$ ), the results of antibacterial activity were read. Diameters of circular inhibition zones were measured with a precision of at least $0.1 \mathrm{~mm}$ using the Readbiotic instrument. The evaluation of antibacterial activities of test samples was carried out in five repetitions.

\subsection{Dilution Method}

Those samples showing antibacterial activity as well as bacterial species showing sensitivity to the applied diffusion method (B. subtilis, P. aeruginosa and S. aureus), were further analyzed by the dilution method. Casein soya bean digest broth (Composition: Pancreatic digest of casein $17.0 \mathrm{~g}$; Papaic digest of soya bean $3.0 \mathrm{~g}$; Sodium chloride $5.0 \mathrm{~g}$; Dipotassium hydrogen phosphate $2.5 \mathrm{~g}$; Glucose monohydrate $2.5 \mathrm{~g}$; Purifies water to $1000 \mathrm{~mL}$ ) was used for investigation of antibacterial activity by the dilution method. Inoculate preparations follows the same procedure as the diffusion method.

\subsubsection{Inoculated Sequence of Diluted Antibacterial Agents (Test Samples)}

Series of doses (eight successive dilutions from 5\% to $0.039 \%$ ) of antibacterial agents (test sample) in geometrical progression were prepared using several test tubes with a nutrient substrate. Dilutions were made using the method of "half the content of test tube" and adding the same volume of the nutrient substrate resulting in geometric progression. The incubation time of prepared dilutions with microorganism was 24 hours.

\subsubsection{Determination of Minimal Inhibitory Concentration (MIC)}

After incubation, determination of minimal inhibitory concentration was carried out according to the opacity of each tube as proof of bacterial growth. In test tubes, where bacterial growth is stopped, the content is transparent. The largest dilution, in the test tube where there was no visible turbidity, is called MIC.

\section{Results}

\subsection{Diffusion Method}

The antibacterial activity of investigated samples and control antibiotics, tested by the diffusion method, is shown in Figures 1-4 and Table 3. 


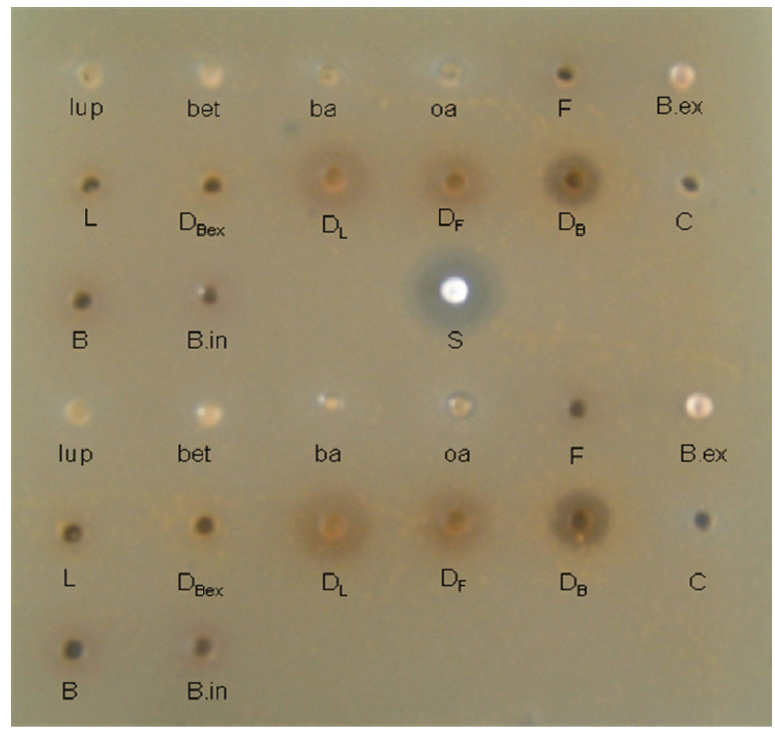

Figure 1. Antibacterial activity of test samples on bacterial strain $S$. aureus

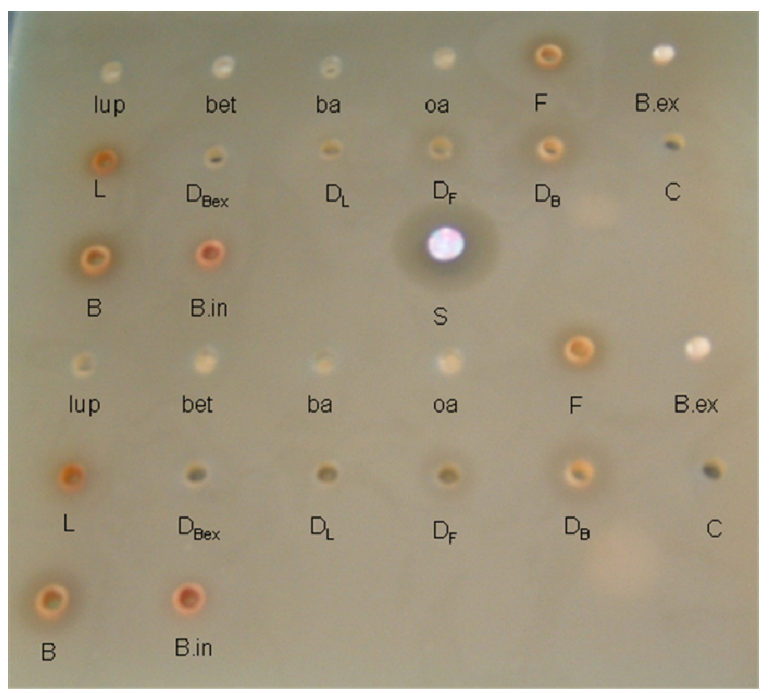

Figure 3. Antibacterial activity of test samples on bacterial strain $E$. coli

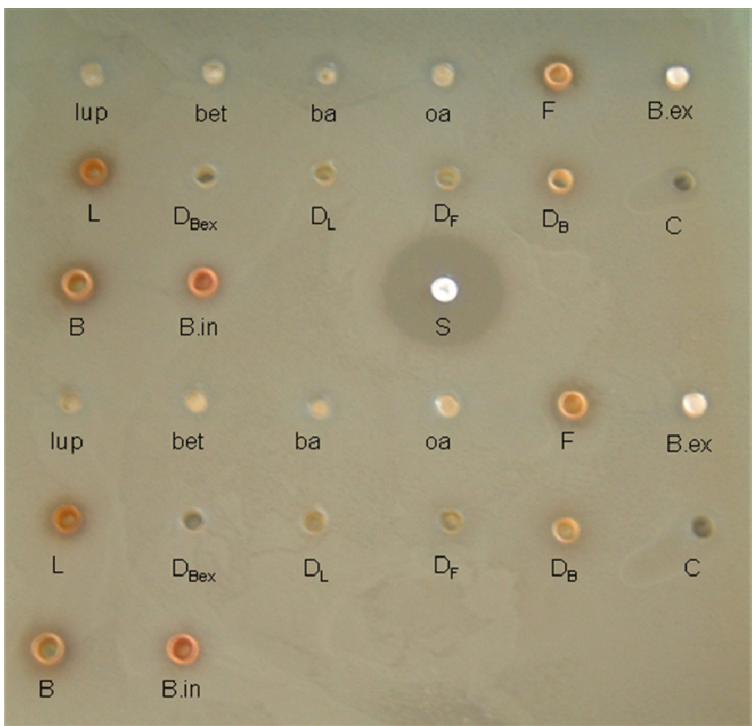

Figure 2. Antibacterial activity of test samples on bacterial strain $P$. aeruginosa

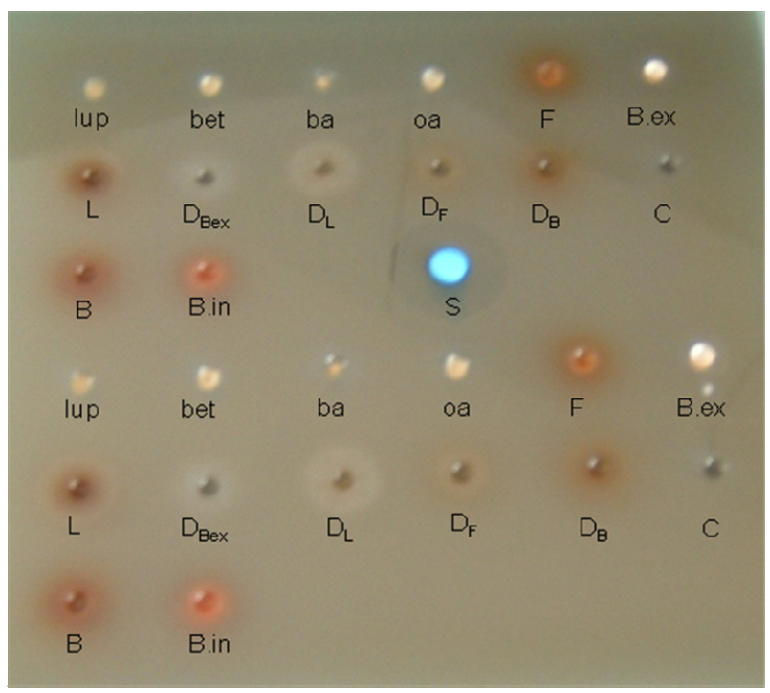

Figure 4. Antibacterial activity of test samples on bacterial strain $B$. subtilis

Decreasing scale of antibacterial activity against $S$. aureus according to inhibition zones was as follows: leaf decoction $(13.4 \mathrm{~mm})$, leaf methanolic extract $(12 \mathrm{~mm})$, buds methanolic extract $(11.2)$, internal bark methanolic extract $(11 \mathrm{~mm})$, flower methanolic extract (10.5), buds decoction (10.2), oleanolic acid (9) and antibiotic Ciprofloksacin $19.5 \mathrm{~mm}$. Other samples did not have significant inhibition zones (Table 3).

Antibacterial activity against $B$. subtilis follows the next decreasing scale: buds and internal bark methanolic extract $(11 \mathrm{~mm})$, oleanolic acid (10.9), flower methanolic extract $(10 \mathrm{~mm})$, buds decoction $(8 \mathrm{~mm})$ and antibiotic Penicilin $32 \mathrm{~mm}$.

P. aeruginosa, showed the following inhibition zones: buds methanolic extract (11.6), flower methanolic extract $(11.2 \mathrm{~mm})$, leaf and internal bark methanolic extract $(11 \mathrm{~mm})$ and external bark methanolic extract $(8 \mathrm{~mm})$ and antibiotic Ciprofloksacin $28 \mathrm{~mm}$.

Against bacteria $E$. coli there was no visible inhibition zone. 
Table 4. Antibacterial activity (inhibition zone measured in $\mathrm{mm}$, including hole of $5 \mathrm{~mm}$ diameter) of test samples by diffusion method

\begin{tabular}{ccccc}
\hline Microorganisms & S. aureus & B. subtilis & P. aeruginosa & E. coli \\
\hline Test samples & \multicolumn{4}{c}{ Inhibition zone $(\mathrm{mm})$} \\
\hline lup & 0.0 & 0.0 & 0.0 & 0.0 \\
bet & 0.0 & 0.0 & 0.0 & 0.0 \\
ba & 0.0 & 0.0 & 0.0 & 0.0 \\
oa & $9.0 \pm 0.00$ & $10.9 \pm 0.44$ & 0.0 & 0.0 \\
F & $10.5 \pm 1.14$ & $10.0 \pm 1.89$ & $11.2 \pm 1.67$ & 0.0 \\
B.ex & 0.0 & 0.0 & $8.0 \pm 0.83$ & 0.0 \\
L & $12.0 \pm 0.83$ & 0.0 & $11.0 \pm 1.92$ & 0.0 \\
$D_{\text {Bex }}$ & 0.0 & 0.0 & 0.0 & 0.0 \\
$D_{\mathrm{L}}$ & $13.4 \pm 0.55$ & 0.0 & 0.0 & 0.0 \\
$\mathrm{D}_{\mathrm{F}}$ & 0.0 & 0.0 & 0.0 & 0.0 \\
$\mathrm{D}_{\mathrm{B}}$ & $10.2 \pm 0.55$ & $8.0 \pm 1.22$ & 0.0 & 0.0 \\
B & $11.2 \pm 0.89$ & $11.0 \pm 0.44$ & $11.6 \pm 1.22$ & 0.0 \\
B.in & $11.0 \pm 0.89$ & $11.0 \pm 0.83$ & $11.0 \pm 0.44$ & 0.0 \\
C & 0.0 & 0.0 & 0.0 & 0.0 \\
$* *$ S & Ciprofloxacin & Penicillin & Ciprofloxacin & Gentamicin \\
& $19.5 \pm 0.42$ & $32.0 \pm 1.92$ & $28.0 \pm 0.55$ & $17.0 \pm 1.22$
\end{tabular}

* The values shown represent the average of five determinations \pm standard deviations; ${ }^{* *} \mathrm{~S}=$ Antibiotic standard.

\subsection{Dilution Method}

\subsubsection{Antibacterial Activity Against P. aeruginosa}

Four extracts showed significant antibacterial activity against $P$. aeruginosa using diffusion method. To determine MIC, a series of dilutions (8 successive concentration) of methanolic extracts from internal bark (B.in), buds (B), leaf (D) and flower (F) were prepared for the investigation of antibacterial activity against P. aeruginosa by the dilution method. The results are given in Table 4.

Table 5. Influence of sample concentration on growth of $P$. aeruginosa

\begin{tabular}{ccccccccc}
\hline \multirow{2}{*}{ Samples } & \multicolumn{8}{c}{ Sample concentration (\%) } \\
\cline { 2 - 9 } & 5 & 2.5 & 1.25 & 0.625 & 0.312 & 0.156 & 0.078 & 0.039 \\
\hline DMSO conc. (\%) & $100 \%$ & $50 \%$ & $25 \%$ & 12.5 & 6.25 & 3.12 & 1.56 & 0.78 \\
C & - & - & - & + & + & + & + & + \\
B.in & - & - & - & $\pm *$ & + & + & + & \\
B & - & - & - & $+*$ & + & + & + & + \\
L & - & - & - & $+*$ & + & + & + & + \\
F & - & - & - & $\pm *$ & + & + & + & +
\end{tabular}

+ visible turbidity (bacterial growth); - non visible turbidity (inhibition of bacterial growth);

\pm partly turbid; * sample sown on nutrient substrate to control bacterial growth. 


\subsubsection{Antibacterial Activity Against B. subtilis}

Three extracts showed antibacterial activity against $B$. subtilis according to diffusion method. Ethanolic extract of internal bark (B. in), buds (B) and solution of oleanolic acid (oa) are used for determination of MIC against B. subtilis by the dilution method. Results of bacterial growth are given in Table 6 .

Table 6. Influence of sample concentration on growth of B. subtilis

\begin{tabular}{ccccccccc}
\hline \multirow{2}{*}{ Samples } & \multicolumn{7}{c}{ Sample concentration (\%) } \\
\cline { 2 - 9 } & 5 & 2.5 & 1.25 & 0.625 & 0.312 & 0.156 & 0.078 & 0.039 \\
\hline DMSO conc. (\%) & 100 & 50 & 25 & 12.5 & 6.25 & 3.12 & 1.56 & 0.78 \\
C & - & - & + & + & + & + & + & + \\
B.in & - & - & $\pm^{*}$ & + & + & + & + & \\
B & - & - & + & + & + & + & + & + \\
oa & - & - & $-*$ & $-*$ & $+*$ & $+*$ & + & + \\
\hline
\end{tabular}

+ visible turbidity (bacterial growth); - non visible turbidity (inhibition of bacterial growth);

\pm partly turbid; * sample sown on nutrient substrate to control bacterial growth.

\subsubsection{Antibacterial Activity Against S. aureus}

The lagest number of extracts (7) showed antibacterial activity against S. aureus. A series of dilutions (8 successive concentrations) of methanolic extracts from internal bark (B.in), buds (B), leaf (L) and flower (F) as well as decoctions of leaf (DL), buds (DB) and a solution of oleanolic acid (oa) were investigated for their MIC on bacterial strain S. aureus. Obtained results are presented in Table 7.

Table 7. Influence of sample concentration on growth of $S$. aureus

\begin{tabular}{ccccccccc}
\hline \multirow{2}{*}{ Samples } & \multicolumn{7}{c}{ Sample concentration (\%) } \\
\cline { 2 - 8 } & 5 & 2.5 & 1.25 & 0.625 & 0.312 & 0.156 & 0.078 & 0.039 \\
\hline DMSO conc. (\%) & 100 & 50 & 25 & 12.5 & 6.25 & 3.12 & 1.56 & 0.78 \\
C (DMSO) & - & - & + & + & + & + & + & + \\
oa & - & - & $-*$ & $-*$ & $+*$ & $+*$ & + & \\
F & - & - & \pm & + & + & + & + & + \\
L & - & - & + & + & + & + & + & + \\
$\mathrm{D}_{\mathrm{L}}$ & - & - & $+*$ & + & + & + & + & + \\
$\mathrm{D}_{\mathrm{B}}$ & - & - & $-*$ & $\pm *$ & $\pm *$ & $\pm *$ & + & + \\
B & - & - & $+*$ & $+*$ & $+*$ & + & + & + \\
B in & - & - & $-*$ & $\pm *$ & $+*$ & + & + & + \\
\hline
\end{tabular}

+ visible turbidity (bacterial growth); - non visible turbidity (inhibition of bacterial growth)

\pm partly turbid; * sample sown on nutrient substrate to control bacterial growth.

During the investigation of antibacterial activity by the dilution method it was apparent that there is inhibition of bacterial growth regardless of the concentration of DMSO in the test tube. Therefore, it was necessary to determine the concentration of DMSO inhibiting bacterial growth in order to exclude its influence on the final results. The concentration of DMSO in the samples ranged from $100 \%$ to $0.78 \%$. In this sense, a series of doses (eight successive dilutions from $100 \%$ to $0.78 \%$ ) of DMSO in geometrical progression were prepared using several test tubes with a nutrient substrate. To this different concentrations of DMSO bacterial inoculums were added. Results show that DMSO has antibacterial activity with different concentration on different microorganisms. The results were presented in Tables 4, 5 and 6. 
By determining the concentration of the solvent (DMSO) which inhibits the growth of test microorganisms ( $P$. aeruginosa $25 \%$; B. subtilis $50 \%$; S. aureus $50 \%$ ) it was possible to determine with a great precision the concentration by which the tested sample inhibits antibacterial activity. In those test tubes, where it was not possible (by visual inspection) to determine the inhibition of bacterial growth, those solutions were sown on bacterial substrate. Taking into account that the solvent DMSO, inhibits P. aeruginosa growth in concentrations greater than $25 \%$, we could consider the samples which have lower concentrations of DMSO. The first lower concentration $(0.625 \%)$ of the investigated samples did not show antibacterial activity against tested microorganism. As a control we sowed tested sample concentrations on a nutrient substrate. The results are given in Figure 5a.

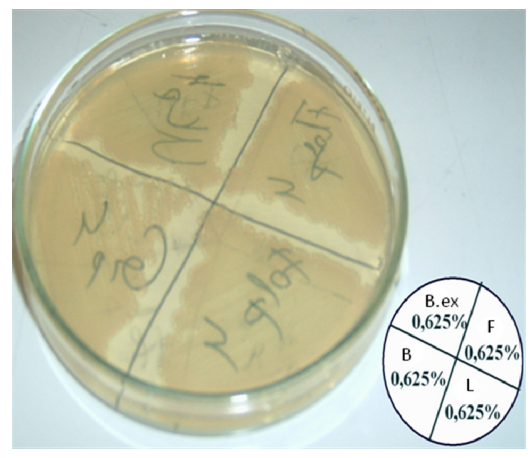

Pseudomonas aeruginosa (a)

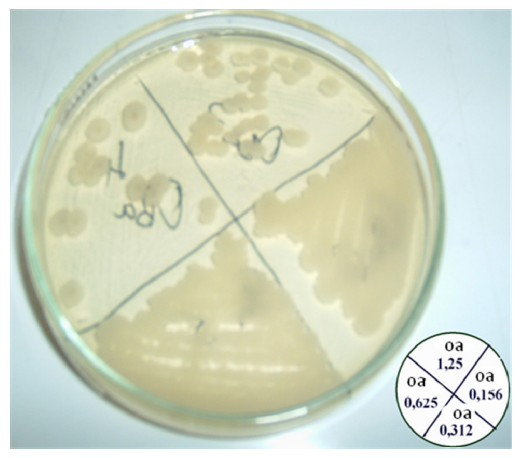

Bacillus subtilis (b)

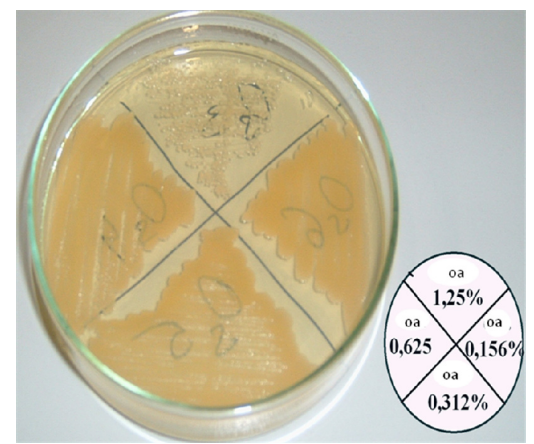

Staphylococcus aureus (c)

Figure 5. Bacterial growth on nutrient substrate

DMSO concentration which inhibits the growth of Bacillus subtilis was $50 \%$, the reason why we took into consideration the samples with lower concentration of DMSO. By sowing on a nutrient substrate, methanolic extract of internal bark and buds have not shown inhibition of growth of tested bacterial species. Positive results were given by oleanolic acid which inhibits the growth of Bacillus subtilis starting from concentration of $0.625 \%$ (Figure 5b). The bacterial species Staphylococcus aureus has shown to be sensitive for great numbers of tested samples. Methanolic extract of flower, leaf, buds and internal bark, decoctions of leaf and buds as well as isolated oleanolic acid all show certain zones of inhibition when applying the diffusion method. The dilution method significantly reduced the number of tested samples, which inhibit the growth of tested bacterial species, where the concentration of DMSO does not overpass 50\%. In fact, excluding the sample concentrations from 5\% and 2.5\%, Staphylococcus aureus has shown to be sensitive to oleanolic acid (concentration 1.25\%) (Figure 5c).

\section{Discussion}

Except decoctions, all samples were applied as solution in DMSO, which has not shown any antibacterial activity when the diffusion method was applied. This can be explained by the fact that DMSO does not penetrate the nutritional substrate used in the diffusion method and therefore does not perform antibacterial activity (Valgas, 2007). Otherwise, the application of the dilution method showed antibacterial activity of DMSO in different concentrations against different test antibacterial strains. Excluding the samples where DMSO concentration exceeds those which inhibit bacterial growth by the solvent itself, we took into consideration the limitation of dilutions of tested samples.

Taking into account that most of the tested samples have inhibitory activity right to the margin of DMSO activity, we could determine only minimal inhibitory concentration (MIC), while the bactericide concentration (MBC) were covered by antibacterial activity of solvent (DMSO).

The results obtained using both methods showed significant activity of birch extracts as well as isolated bioactive compounds. The fact that one of the therapeutic indications for birch drugs is in the case of inflammation and renal gravel and as an adjuvant in the treatment of bacterial infections of the urinary tract, may additionally justify its use as antibacterial (ESCOP, 2003).

It was of interest to note the fact that the inhibition was higher for Gram positive than for Gram negative microorganisms (Table 3), which is in accordance with literature datas (Basic, 1998). The bacterial strain E. coli 
was found to be resistant to all test samples.

Based on previous studies, triterpene compounds betulin, betulinic acid, lupeol and oleanolic acid have proven to have antibicrobial activity (Silva, 2012). In this work, both diffusion and dilution method confirmed antibacterial activity of oleanolic acid against $\mathrm{S}$. aureus and B. subtilis.

Bacterial strain S. aureus showed sensitivity to the largest number of test samples. Given the fact that decocts is the most frequent pharmaceutical form of application, a very important results was the antibacterial activity on bacterial strain S. aureus shown by leafs and buds decocts.

\section{Conclusion}

In the application of diffusion and dilution methods of analysis, oleanolic acid was shown to be most efficient against bacterial species Staphylococcus aureus (MIC: 1.25\%) and Bacillus subtilis (MIC: 0.625\%). According to the results of the diffusion method, certain antibacterial activity against Staphylococcus aureus showed methanolic extracts of the leaf, buds and flower as well as leaf and buds decoctions.

Methanolic extracts of the internal bark, buds and flower showed a zone of inhibition against Bacillus subtilis. Antibacterial activity against Gram-negative bacteria, more precisely against Pseudomonas aeruginosa, showed methanolic extracts of the internal bark, buds, leaf and flower. Gram-negative bacteria, Escherichia coli showed resistance to all applied test samples.

The results indicate that the antibacterial and antimicrobial activity of different birch parts in general should be further explored when used as herbs and in herbal preparations. Also the use of birch in prevention and treatment of various human infections seems quite useful and reasonable.

\section{References}

Basic, F., \& Beslagic, E. (1998). Mikrobiologija, morfoloski aspekti sa dijagnostikom. Sarajevo, B\&H: Medicnski fakultet Sarajevo.

Bruneton, J. (1999). Pharmacognosy, Phytochemistry medicinal plants. Paris: Tec\$Doc.

Dehelean, C. A., Oica, C. A., Lede, I. I., Alua, M., Zupko, I. G., Lu Can, A., ... Munteanu, M. (2012). Study of the betulin enriched birch bark extracts effects on human carcinoma cells and ear inflammation. Chem Cent J., 19, 6(1), 137. http://dx.doi.org/10.1186/1752-153X-6-137

Drag, M., Surowiak, P., Drag-Zalesinska, M., Dietel, M., Lage, H., \& Oleksyszyn, J. (2009). Comparison of the cytotoxic effects of birch bark extract, betulin and betulinic acid towards human gastric carcinoma and pancreatic carcinoma drug-sensitive and drug-reistan cell lines. Molecules, 24, (4), 1639-51. http://dx.doi.org/10.3390/molecules14041639

European Pharmacopoeia Convention. (1996). European Pharmacopoea. Council of Europe. Strasbourg, France: Cedex.

European Scientific Cooperative on Phytotherapy. (2003). ESCOP monographs. Exter, United Kingdom: The Scientific Foundation for Herbal Medicinal Products, Argyle House.

Germanò, M. P., Cacciola, F., Donato, P., Dugo. P., Certo, G., D' Angelo, V., ... Rapisarda, A. (2012). Betula pendula leaves: polyphenolic characterization and potential innovative use in skin whitening products. Fitoterapia, 83(5), 877-82. http://dx.doi.org/10.1016/j.fitote.2012.03.021

Grainger, N. B., \& Wichtl, M. (2001). Herbal Drugs and Phytopharmaceuticals. Stuttgart, Gemany: Medpharm GmH Scientific Publisher. Retrieved from http://www.ncbi.nlm.nih.gov/pubmed/21377854

Dorr, C. R., Yemets, S., Kolomitsyna, O., Krasutsky, P., Mansky, L. M. Triterpene Derivatives that Inhibit Human Immunodeficiency Virus Type 1 Replication. (2011). Bioorg. Med. Chem. Lett., 1, 21(1), 542-545. http://dx.doi.org/10.1016/j.bmcl.2010.10.078

Kovac-Besovic, E., Duric, K., Kalodera, Z., \& Sofic, E. (2009). Identification and isolation of pharmacologically active triterpenes in Betulae cortex, Betula pendula Roth., Betulaceae. Bosnian Journal of Basic Medical Sciences, 9(1), 31-38. http://www.ncbi.nlm.nih.gov/pubmed/19284392

Shikov, A. N., Djachuk, G. I., Sergeev, D. V., Pozharitskaya, O. N., Esaulenko, E. V., Kosman, V. M., \& Makarov, V. G. (2011). Birch bark extract as therapy for chronic hepatitis C-a pilot study. Phytomedicine, 18(10), 807-10. http://dx.doi.org/10.1016/j.phymed.2011.01.021

Silva, M. L., David, J. P., Silva, L. C. R. C., Santos, R. A. F., David, J. M., Lima, L. S., .. Fontana, R. (2012). Bioactive Oleanane, Lupane and Ursane Triterpene Acid Derivatives. Molecules, 17, 12197-12205. 
http://dx.doi.org/10.3390/molecules171012197

Soica, C. M., Dehelean, C. A., Peev, C., Aluas, M., Zupkó, I., Kása, P. Jr., \& Alexa, E. (2012). Physico-chemical comparison of betulinic acid, betulin and birch bark extract and in vitro investigation of their cytotoxic effects towards skin epidermoid carcinoma (A431), breast carcinoma (MCF7) and cervix adenocarcinoma (HeLa) cell lines. Nat. Prod. Res., 26(10), 968-74. http://dx.doi.org/10.1080/14786419.2010.545352

The European Pharmacopoeia Convention, Council of Europe. (1996). European Pharmacopoea. Strasbourg, France: Cedex.

Valgas, C., Souza, S. M., Smânia, E. F. A., \& Smânia, A. (2007). Screening methods to determine antibacterial activity of natural products. Brazilian Journal of Microbiology, 38, 369-380. http://dx.doi.org/10.1590/S1517-83822007000200034

\section{Copyrights}

Copyright for this article is retained by the author(s), with first publication rights granted to the journal.

This is an open-access article distributed under the terms and conditions of the Creative Commons Attribution license (http://creativecommons.org/licenses/by/3.0/). 